\title{
A study in Bundelkhand region of Madhya Pradesh, India to assess the risk factors and correlates of pre-eclamptic toxemia
}

\author{
Shikha Pandey ${ }^{1 *}$, Ramesh Pandey ${ }^{2}$
}

\author{
${ }^{1}$ Department of Obstetrics and Gynecology, Bundelkhand Medical College, Sagar, Madhya Pradesh, India \\ ${ }^{2}$ Department of Medicine, Bundelkhand Medical College, Sagar, Madhya Pradesh, India
}

Received: 23 February 2017

Accepted: 27 February 2017

\author{
*Correspondence: \\ Dr. Shikha Pandey, \\ E-mail: drshikhabmc2013@gmail.com
}

Copyright: (C) the author(s), publisher and licensee Medip Academy. This is an open-access article distributed under the terms of the Creative Commons Attribution Non-Commercial License, which permits unrestricted non-commercial use, distribution, and reproduction in any medium, provided the original work is properly cited.

\begin{abstract}
Background: Pre-eclamptic toxemia is pregnancy-induced hypertension (PIH) manifesting in second trimester and affecting multiple systems. The objective was to study the factors of pre-eclampsia in pregnant women admitted for delivery in Bundelkhand Medical college hospital Sagar, Madhya Pradesh, India.

Methods: A case-control study was conducted at Bundelkhand Medical College Hospital in Sagar, Madhya Pradesh, India. Criteria in selection of pregnant women with pre-eclampsia comprised those who had hypertension after the $20^{\text {th }}$ week of gestation with associated proteinuria, and controls were pregnant women who were not diagnosed with pre-eclampsia. Total of 100 cases and 100 controls were selected for the year 2015. Factors in study included mother's age, parity, body mass index, history of chronic hypertension, history of diabetes, history of renal disease, family history of hypertension, and history of pre-eclampsia in earlier pregnancy. Crude and adjusted odds ratio with $95 \%$ CI and Chi-square test were used for statistical analysis.

Results: Major risk factors identified in univariate analysis included before pregnancy body mass index $(\mathrm{BMI}>25)$ $(\mathrm{OR}=11.27)$, history of hypertension $(\mathrm{OR}=8.65)$, history of diabetes mellitus $(\mathrm{OR}=11.0)$, history of renal disorders $(\mathrm{OR}=7.98)$, familial history of hypertension $(\mathrm{OR}=5.4)$, history of PIH in earlier pregnancy $(\mathrm{OR}=9.63)$, and twin pregnancy $(\mathrm{OR}=4.85)$. As per multiple logistic regression analysis the pre-pregnancy $\mathrm{BMI}$ of $>25(\mathrm{OR}=7.56)$, history of hypertension $(\mathrm{OR}=6.69)$, history of diabetes mellitus $(\mathrm{OR}=8.66)$, history of renal disease $(\mathrm{OR}=5.6)$, family history of hypertension $(\mathrm{OR}=5.48)$, and twin pregnancy $(\mathrm{OR}=5.73)$ are the significant risk factors of pre-eclampsia.

Conclusions: The pregnant women at risk of pre-eclampsia should be identified early and high-quality antenatal care should be provided in order to minimize the complications of pre-eclampsia both for the mother and the fetus.
\end{abstract}

Keywords: Antenatal care, Case control study, Pre-eclampsia, Risk factors, Twin pregnancy

\section{INTRODUCTION}

Pre-eclamptic toxemia is pregnancy-induced hypertension $(\mathrm{PIH})$ manifesting in second trimester and affecting multiple systems. Etiology is unknown. Preeclampsia may be quite serious. It can lead to various complications both for the mother and the baby. Preeclampsia and eclampsia are the leading cause of infant and maternal death in Bundelkhand, Madhya Pradesh, India. Hypertension complicates an estimated 6-8\% of all pregnancies. There are significant differences in the incidence of hypertensive disorders of pregnancy in the populations of Southeast Asia. Also, the fact is that these are not due to differences in the baseline blood pressures in these populations. ${ }^{1}$

Certain risk factors are associated with PET. The factors that are associated with pre-eclampsia among the mothers include diabetes, renal disease, primiparity, chronic hypertension, age above 30 years, obesity, multiple pregnancies and personal or family history of preeclampsia. 
In developing countries, proof of the relation between these factors and pre-eclampsia is not easily available. There are several studies in developed and some developing countries to establish the association between these factors and pre-eclampsia. ${ }^{2-5}$ Those which have been conducted have often had an inappropriate control and weak statistics. This shows insufficient evidence for determinants of pre-eclampsia in developing countries. Little studies have been conducted in India to assess the risk factors of pre-eclampsia. Studies like this will be a useful tool to take appropriate interventional measures. In this reference, a case-control study was conducted BMC to assess and determine the risk factors for pre-eclampsia.

\section{METHODS}

This study was conducted in Bundelkhand Medical College Hospital Sagar Madhya Pradesh, India. This is a tertiary care hospital and caters to the needs of multiple peripheral health centers around the district. 100 cases and 100 controls were selected for the year 2015. This is calculated by taking odds ratio of 3 , power at $80 \%$, significant level was 0.05 , and controls with exposure were 0.1 proportions. Pregnant women with PET comprised those with hypertension after the $20^{\text {th }}$ week of gestation along with proteinuria, and controls were pregnant women not diagnosed with PET. Cases and controls were selected following the above criteria ensuring a case control ratio of 1:1. Maternal records of the hospital from January to December 2015 were studied for history and case work up. Firstly, maternal records of pre-eclampsia patients were studied and separated. Cases were selected from the separated pre-eclampsia records randomly. In the same manner controls were selected. Information relating age, parity, body mass index (BMI), twin pregnancy, history of chronic hypertension, history of diabetes, history of renal dysfunction and history of $\mathrm{PIH}$ in earlier pregnancy was obtained from the case records. Records were analyzed by using of SPSS version 12. Adjusted and Crude odds ratios with $95 \%$ confidence intervals. A multiple logistic regression analysis is used to assess independent effects of each variable.

\section{RESULTS}

Most of the controls and cases were in the 20-29-year age group (76\% and $85 \%$ ). Body mass index was normal among the majority of the cases and controls. Around $15 \%$ of cases and $2 \%$ of controls had chronic hypertension. The percentage of multigravida was high among cases as compared to controls. On analysing we found that multiple pregnancy $(\mathrm{OR}=4.85)$, history of chronic hypertension $(\mathrm{OR}=8.65), \mathrm{BMI} \geq 25(\mathrm{OR}=11.27)$, history of renal disease $(\mathrm{OR}=7.98$, history of diabetes $(\mathrm{OR}=11.0)$, family history of hypertension $(\mathrm{OR}=5.4)$, history of PIH in earlier pregnancy (9.63), and were associated significantly with PET. Age group was not associated significantly with pre-eclampsia in present study (Table 1).
Table 1: Risk factors for pre-eclamptic toxemia-a univariate study.

\begin{tabular}{|c|c|c|c|c|}
\hline Factors & Cases & Control & Crude OR & $95 \% \mathrm{CL}$ \\
\hline \multicolumn{5}{|c|}{ History of PIH in earlier pregnancy } \\
\hline Present & 10 & 1 & 9.63 & $1.15-80.63$ \\
\hline Absent & 27 & 26 & ---- & --- \\
\hline \multicolumn{5}{|c|}{ Body mass index } \\
\hline$>25$ & 13 & 3 & 11.27 & $2.22-57.20$ \\
\hline $18.5-24.9$ & 82 & 84 & 2.54 & $0.86-7.44$ \\
\hline$<18.5$ & 5 & 13 & -- & --- \\
\hline \multicolumn{5}{|l|}{ Age } \\
\hline $20-29$ & 76 & 85 & 0.56 & $0.27-1.14$ \\
\hline$>30$ & 24 & 15 & .. & -- \\
\hline \multicolumn{5}{|c|}{ Multiple pregnancy } \\
\hline Present & 9 & 2 & 4.85 & $1.02-23.03$ \\
\hline Absent & 91 & 98 & --- & --- \\
\hline \multicolumn{5}{|c|}{ Chronic hypertension } \\
\hline Present & 15 & 2 & 8.65 & $1.92-38.90$ \\
\hline Absent & 85 & 98 & --- & --- \\
\hline \multicolumn{5}{|l|}{ Renal disease } \\
\hline Present & 10 & 1 & 11.0 & $1.38-87.64$ \\
\hline Absent & 90 & 99 & --- & ---- \\
\hline \multicolumn{5}{|c|}{ Family history of hypertension } \\
\hline Present & 14 & 2 & 7.98 & $1.76-36.09$ \\
\hline Absent & 86 & 98 & --- & ---- \\
\hline \multicolumn{5}{|l|}{ Parity } \\
\hline Multigravida & 37 & 27 & 1.59 & $0.87-2.89$ \\
\hline Primigravida & 63 & 13 & $\ldots \ldots$ & -- \\
\hline
\end{tabular}

Table 2: Related conditions in PET: multiple logistic regression analysis.

\begin{tabular}{|c|c|c|c|}
\hline Factors & Adjusted OR & $95 \% \mathrm{CL}$ & P-value \\
\hline \multicolumn{4}{|l|}{ Parity } \\
\hline Multigravida & 1.89 & $0.96-3.70$ & 0.07 \\
\hline Primigravida & ---- & --- & -- \\
\hline \multicolumn{4}{|c|}{ Body mass index } \\
\hline$\geq 25$ & 7.56 & $1.32-43.37$ & 0.02 \\
\hline $18.5-24.9$ & 1.86 & $0.6-5.77$ & 0.29 \\
\hline \multicolumn{4}{|l|}{$<18.5$} \\
\hline \multicolumn{4}{|c|}{ Multiple pregnancy } \\
\hline present & 5.73 & $1.13-29.10$ & $0.04 *$ \\
\hline Absent & -- & & \\
\hline \multicolumn{4}{|c|}{ History of chronic hypertension } \\
\hline present & 6.69 & $1.37-32.75$ & $0.02 *$ \\
\hline Absent & -- & ----- & ---- \\
\hline \multicolumn{4}{|c|}{ History of diabetes } \\
\hline present & 8.66 & $1.01-76.26$ & $0.05^{*}$ \\
\hline Absent & -- & ---- & ---- \\
\hline \multicolumn{4}{|c|}{ History of renal disease } \\
\hline present & 5.6 & $1.12-28.04$ & $0.04 *$ \\
\hline Absent & -- & ---- & --- \\
\hline \multicolumn{4}{|c|}{ Family history of hypertension } \\
\hline present & 5.48 & $1.09-27.55$ & $0.04 *$ \\
\hline Absent & --- & ---- & ----- \\
\hline
\end{tabular}


After adjustment for confounding variables, six variables were associated with PET in multivariate logistic regression analysis. The significant determinants identified for PET were history of chronic hypertension $(\mathrm{OR}=6.69)$, history of diabetes $(\mathrm{OR}=8.66)$, pre-pregnancy BMI of $\geq 25 \quad(\mathrm{OR}=7.56)$, history of renal disease $(\mathrm{OR}=5.6)$, family history of hypertension $(\mathrm{OR}=5.48)$ and twin pregnancy $(\mathrm{OR}=5.73)$. The most important factors in the occurrence of PET were BMI, diabetes, and history of chronic hypertension (Table 2).

\section{DISCUSSION}

This study has been conducted in B.M.C. Hospital attached to a medical institution. Most of the deliveries in the district are home deliveries with the aid of MPW (Multi-Purpose Workers)/dais or conducted in government and private hospitals. There is no proper system that can record the history at home, majority of hospital and public sectors like primary health centers and community health centers. Unavailability of databases, this study has been conducted in a medical college hospital. This study excludes births in private hospitals clinics and at home.

Present study showed that the pre-pregnancy BMI of $\geq 25$, history of chronic hypertension, history of diabetes, history of renal dysfunction, family history of hypertension, and twin pregnancy were significant independent risk factor for PET. In India, welldocumented studies to assess the risk factors of preeclampsia are few. ${ }^{6}$ Multiple studies established that prepregnancy BMI is an important risk factor for preeclampsia. ${ }^{2,3,7}$ Hypertension is a common problem in developing countries in non-pregnant women and increases the incidence of pre-eclampsia. We found that chronic hypertension is one of the main risk factor of preeclampsia. It has also been found to be a major risk factor for pre-eclampsia in several other studies. ${ }^{5,8}$ Family history of hypertension was also associated independently with PET. ${ }^{9,10}$

Renal dysfunction and Diabetes are well-known for adverse pregnancy outcomes. In this study both of these factors were independently related with preeclampsia. The possibility of pre-eclampsia nearly increases by 8.7 times in pre-pregnancy diabetics. The predicted probability of pre-eclampsia was estimated to be $<0.05$ for those with family history of diabetes. Similar findings were also found in other studies. ${ }^{5,11}$ Renal dysfunction is found to be a risk factor for pre-eclampsia in other studies. ${ }^{5,12}$ This study found that twin pregnancy increases the risk of pre-eclampsia by 5.7 times. Other studies showed the risk to increase by 3.5 times. ${ }^{2,13}$ In this study age and parity were not found to be linked with preeclampsia. ${ }^{3,14}$

One study of Saudi Arabia showed that, the nulliparous women, women at extremes of maternal age and high- parity women are at higher risk of developing preeclampsia. ${ }^{14}$

The difference in the present study and other studies could be due to the differences in the hospital-based study and population based. Second reason could be the inclusion of mothers from the lower socioeconomic group who attended the hospital. These mothers were found to be at lower risk.

Most of the cases and controls admitted were from the lower and middle socioeconomic group; hence it can be biased to an extent. But in other hospitals, selection bias may be more, where more affluent urban population attends. This study provides information, which can be quite helpful in planning maternity services at a district level to prevent the complications for the mother and the baby. Looking at the above findings, it is concluded that pregnant women who are at risk of pre-eclampsia should be identified. High-quality maternity services should be given in order to minimize the complications of preeclampsia for the mother and the baby. This may play a role in bringing down MMR. For the betterment of maternity health services, we advise the health department to strengthen the maternal health programs focusing on the prevention and control of the risk factors. At the same time, corrective therapeutic measures are advised for the mothers who are at risk by means of exercises and right nutrition.

\section{CONCLUSION}

All the antenatal women who are at high risk for preeclampsia should be identified and appropriate good quality antenatal care should be provided to them so as to prevent maternal and fetal complication.

Funding: No funding sources

Conflict of interest: None declared

Ethical approval: The study was approved by the Institutional Ethics Committee

\section{REFERENCES}

1. Geographic variation in the incidence of hypertension in pregnancy. World Health Organization International Collaborative Study of Hypertensive Disorders of Pregnancy. Am J Obstet Gynecol. 1988;158(1):80-3.

2. Lee CJ, Hsieh TT, Chiu TH, Chen KC, Lo LM, Hung TH. Risk factors for pre-eclampsia in an Asian population. Int J Gynaecol Obstet. 2000;70(3):32733.

3. Eskenazi B, Fenster L, Sidney S. A multivariate analysis of risk factors for preeclampsia. JAMA. 1991;266(2):237-41.

4. Mahomed K, Williams MA, Woelk GB, JenkinsWoelk L, Mudzamiri S, Madzime S, et al. Risk factors for preeclampsia-eclampsia among Zimbabwean women: Recurrence risk and familial 
tendency towards hypertension. J Obstet Gynaecol. 1998;18:218-22.

5. Duckitt K, Harrington D. Risk factors for preeclampsia at antenatal booking: systematic review of controlled studies. BMJ. 2005;330(7491):565.

6. Amir A, Mohd Y, Islam HM. Clinico epidemiological study of factors associated with pregnancy induced hypertension. Indian J community Med. 1998;23:25-9.

7. Thadhani R, Stampfer MJ, Hunter DJ, Manson JE, Solomon CG, Curhan GC. High body mass index and hypercholesterolemia: risk of hypertensive disorders of pregnancy. Obstet Gynecol. 1999;94(4):543-50.

8. Davies AM, Czaczkes JW, Sadovsky E, Prywes R, Weiskopf P, Sterk VV. Toxemia of pregnancy in Jerusalem. I. Epidemiological studies of a total community. Isr J Med Sci. 1970;6(2):253-66.

9. Qiu C, Williams MA, Leisenring WM, Sorensen TK, Frederick IO, Dempsey JC, et al. Family history of hypertension and type 2 diabetes in relation to preeclampsia risk. Hypertension. 2003;41(3):408-13.

10. Ness RB, Markovic N, Bass D, Harger G, Roberts JM. Family history of hypertension, heart disease, and stroke among women who develop hypertension in pregnancy. Obstet Gynecol. 2003;102(6):1366-71.

11. Bryson CL, Ioannou GN, Rulyak SJ, Critchlow C. Association between gestational diabetes and pregnancy-induced hypertension. Am J Epidemiol. 2003;158(12):1148-53.

12. Davies AM, Czaczkes JW, Sadovsky E, Prywes R, Weiskopf P, Sterk VV. Toxemia of pregnancy in Jerusalem. I. Epidemiological studies of a total community. Isr J Med Sci. 1970;6(2):253-66.

13. Coonrod DV, Hickok DE, Zhu K, Easterling TR, Daling JR. Risk factors for preeclampsia in twin pregnancies: a population-based cohort study. Obstet Gynecol. 1995;85(5 Pt 1):645-50.

14. Lawoyin TO, Ani F. Epidemiologic aspects of preeclampsia in Saudi Arabia. East Afr Med J. 1996;73(6):404-6.

Cite this article as: Pandey S, Pandey R. A study in Bundelkhand region of Madhya Pradesh, India to assess the risk factors and correlates of pre-eclamptic toxemia. Int J Reprod Contracept Obstet Gynecol 2017;6:1249-52. 